Çukurova Üniversitesi Mühendislik Mimarlık Fakültesi Dergisi, 31(2), ss. 401-414, Aralık 2016

\title{
Bronz Yapitların Atmosferik Korozyonunda Hava Kirleticilerin Etkisi ve İnhibitörle Korunması
}

\author{
Gözde TANSUĞ $\breve{G}^{* 1}$ \\ ${ }^{l}$ Çukurova Üniversitesi Ceyhan Mühendislik Fakültesi Kimya Mühendisliği Bölümü, Adana
}

Geliș tarihi:13.06.2016

Kabul tarihi: 23.11.2016

$\ddot{\mathbf{O} z}$

Arkeolojik ve modern yapitlarda sıkça karşılaşılan bronz malzemenin atmosferik korozyonu, havada bulunan kirleticiler ve diğer meteorolojik verilerle ilişkilendirilerek çalışılmıştır. Bronz yüzeyinin atmosferik korozyona karşı uzun süreli korunmasını sağlamak için organik inhibitör etkinlikleri test edilmiştir. İnhibitörün kimyasal adsorpsiyonu ile oluşan polimerik filmin oksit birikintisi ile uyumlu olduğu ve bu yolla atmosferik korozyona karşı etkin bir koruma sağlanabileceği gösterilmiştir.

Anahtar Kelimeler: Atmosferik korozyon, Bronz, Hava kirleticiler, İnhibitör

\section{The Influence of Air Pollutants on the Atmospheric Corrosion of Bronze Artefacts and Protection with Inhibitor}

\begin{abstract}
Atmospheric corrosion of bronze has been investigated in presence of air pollutants, since this material is widely preferred for construction of artefacts, in relation with meteorological parameters. The data showed that bronze surface could be protected with organic thin film which is also compatible with natural oxides. Polymer-like organic films were obtained on the surface, thanks to chemisorption of organic inhibitor molecules. The said layer was shown to exhibit high protection efficiency against atmospheric corrosion.
\end{abstract}

Keywords: Atmospheric corrosion, Bronze, Air pollutants, Inhibitor

\footnotetext{
*Sorumlu yazar (Corresponding author): Gözde TANSUĞ, gtansug@cu.edu.tr
} 


\section{GíRiş}

Bakır ve alaşımlarından üretilmiş olan kültürel yapıtlar, şehir atmosferine maruz kaldıklarında zamanla korozyona uğramakta ve tahrip olmaktadırlar. Atmosferik korozyon hem estetik kaybına hem de kalıcı deformasyona neden olmaktadır [1]. Bu süreçte, endüstriyel gazların atmosferdeki varlığı ve partikül halinde havada bulunan kirliliklerin önemi çok büyüktür. Her türlü yakıtların evsel ve endüstriyel kullanımı sonucu havaya karışan $\mathrm{SO}_{\mathrm{x}}$ ve $\mathrm{NO}_{\mathrm{x}}$ 'lerin suyla tepkimesi sonucu oluşan asit yağmurları, atmosferik korozyonu doğrudan hızlandıran bir etkiye sahiptir. Duman, toz benzeri kirleticilerle birlikte bu asitlerin tahrip edici etkisi çok daha artmaktadır. Bir diğer önemli etken ise ozon gazının kendisidir, bu gaz fotokimyasal sisin temel bileşenidir. Atmosferik kirlilikler metallerin yüzeyinde kararlı (koruyucu) patina oluşmasını engellerken, çukurcuklara, şekil bozukluklarına, varsa yüzeydeki kaplamaların tahrip olmasına neden olurlar. Sıcaklık ve güneş ışığının etkisi ile termal ve fotokimyasal hasarın da ortaya çıktığı bilinmektedir [2-5].

Partikül madde (PM) boyut, oluşum mekanizması, köken, kimyasal bilesim, atmosferik davranış ve ölçüm yöntemi ile tanımlanan kimyasal ve fiziksel olarak farklı maddelerin karışımlarıdır. Atmosferde bir kez yer aldıktan sonra çeşitli etkilerle (sanayileşme, nüfus artışı, vs.) konsantrasyon ve boyutları değişir. Çevresel atmosferdeki kirleticilerin derişim dağılımı, emisyonun yöre, yerden yükseklik, h1z, sicaklık gibi faktörlere bağlı olarak belirlenmektedir. Hava faktörlerinin sinerjistik etkileşimleri de göz önüne alınmalıdır; yapıtlar üzerinde hacimsel değişimlere ve malzemede bozunmalara, çatlakların yayılmasına neden olmaktadır. Aşındırıcı partiküller ve rüzgâr yüzeyi tahrip etmekte, nem + rüzgâr + su + kirleticiler zayıf asitleri oluşturarak, bunların malzemelerin içine işlemesine neden olmaktadır [6,7].

Birçok kirliliğin ve meteorolojik parametrelerin (sıcaklık, nem, rüzgar, güneşlenme süresi vb.) olası etkilerinin açıklanmış olmasına rağmen, metalin türüne bağlı olarak atmosferik korozyon sürecinin mekanizma, hız açısından aydınlatılmasına ihtiyaç duyulmaktadır.

Atmosferdeki su buharının malzeme yüzeyinde fiziksel adsorpsiyonu sonucu oluşan nem tabakası atmosferik korozyonun başlaması için gerekli ilk adımdır [8,9]. Bu nem tabakasının yüzeyde kalma süresi ve kimyasal bileşimi (iyonlar, çözünmüş gaz vb.) çevresel faktörlere ve meteorolojik parametrelere bağlıdır [10]. Nem tabakası (filmi) içerisindeki korozif bileşenler ve diğer türlerin yüzeyle etkileşmeleri doğrudan oransal miktarları ile ilgili olup, atmosferik korozyonun h1z1 ve mekanizması açısından belirleyicidir [8]. Havadaki nem oranı belli bir değerin üzerinde olduğunda, hava sıcaklığındaki ani değişimler sonucu ortaya çıkan çiğ, metalik yüzey üzerinde ince bir nem tabakası (film) oluşturur. Atmosferdeki kirlilik derişimi göreceli yüksek olduğu durumda, yağmura göre bu koşullar çok daha koroziftir [10].

Literatürde bakır korozyonu üzerinde atmosferik $\mathrm{NO}_{2}$ ve/veya $\mathrm{SO}_{2}$ kirleticileri ile bağıl nemin etkisi sıklıkla incelenmiştir [11-13]. $\mathrm{SO}_{2}$ gazının varlığı bakırın korozyonunu hızlandırmakta, metal yüzeyindeki nem tabakası içinde oluşan sülfüröz $\left(\mathrm{H}_{2} \mathrm{SO}_{3}\right)$ ve sülfürik $\left(\mathrm{H}_{2} \mathrm{SO}_{4}\right)$ asit patinanın komposizyonunu etkilemektedir [14]. Açık atmosfer koşullarında uzun süreli kalan patina içinde sülfitler ve sülfatlar bulunmaktadır. pH'ın 4 den büyük olduğu durumlarda bakır sülfat $\left(\mathrm{Cu}_{4}\left(\mathrm{SO}_{4}\right)(\mathrm{OH})_{6}\right)$ tabakası kararlı halde yüzeyde oluşmaktadır. $\mathrm{NO}_{2}$ gazı suda az da olsa çözünebilen bir gaz olmasına rağmen nitröz ve nitrik asit olarak bakır yüzeyinde indirgenmektedirler. $800 \mu \mathrm{g} / \mathrm{m}^{3} \mathrm{SO}_{2}$ ve $\mathrm{NO}_{2}$ 'nin varlığı, \%90 bağıl nem koşullarında patinanın üzerinde belirgin bir renk değişikliğine neden olmamaktadır. \%90 bağıl nem koşullarında $\mathrm{NO}_{2}$, $\% 90$ ve $\% 50$ bağıl nem koşullarındaki $\mathrm{SO}_{2}$ den daha az koroziftir. Ancak \%50 bağıl nem koşullarındaki $\quad \mathrm{NO}_{2}$ 'nin korozifliğinin $\mathrm{SO}_{2}$ 'ninkinden yüksek olduğu gösterilmiştir.

$2000 \mu \mathrm{g} / \mathrm{m}^{3}$ değerinden yüksek $\mathrm{SO}_{2}$ ve $\mathrm{NO}_{2}$ 'nin, $\% 90$ değerinden yüksek bağıl nemin korozyon hızı üzerine sinerjik etki yarattığı tespit edilmiştir. Bu durumda $\mathrm{Cu}_{2} \mathrm{O}$ fillmi zamanla çözünmektedir ve 
sülfür bileşikleri bakır yüzeyinde oluşmaktadır. $\mathrm{SO}_{2}$ ve $\mathrm{NO}_{2}$ 'nin Eşitlik 1'deki reaksiyonu bağıll nemin fazla olduğu ortamlarda gerçekleşmektedir [12].

$$
\mathrm{SO}_{2}+2 \mathrm{NO}_{2}+2 \mathrm{H}_{2} \mathrm{O} \rightleftarrows 2 \mathrm{H}^{+}+\mathrm{SO}_{4}{ }^{2-}+2 \mathrm{HNO}_{2}
$$

Literatürde ozonun $\left(\mathrm{O}_{3}\right) 1 \mathrm{mg} / \mathrm{L}$ değerini aşması bakır alaşımlarının korozyon hızını 5-10 kat artırdığı bildirilmiştir [15]. Bakır ve alaşımları üzerinde yapılan başka bir çalışmada, ozonun 0.05 $\mathrm{mg} / \mathrm{L}$ varlığının ise metal yüzeyinde koruyucu oksit tabaka oluşumunu katalizleyerek, korozyona karşı direnci arttırdığ 1 bulunmuştur [16]. Başka bir çalışmada, atmosferik korozyonda en etkili parametre olarak rapor edilen $\mathrm{NO}_{2}$, taşıt motorlarından yanma ürünü olarak açığa çıkarak, bakır malzeme üzerindeki nem ile birleşerek nitröz asit oluşumuna dair meydana gelen tepkimeler aşağıda verilmiştir. Ortamdaki oksijenin varlığı ile nitröz asit yükseltgenerek nitrik asite dönüşmektedir (Eşitlik 2 ve 3) [3].

$$
\begin{aligned}
& 2 \mathrm{Cu}_{(\mathrm{k})}+2 \mathrm{NO}_{2(\mathrm{~g})}+2 \mathrm{H}_{2} \mathrm{O}_{(\mathrm{ads})} \rightarrow \mathrm{Cu}_{2} \mathrm{O}_{(\mathrm{k})}+\mathrm{HONO}_{\text {(suda) }} \\
& 2 \mathrm{HONO}_{\text {(suda) }}+\mathrm{O}_{2}(\mathrm{~g}) \rightarrow 2 \mathrm{HNO}_{3 \text { (suda) }}
\end{aligned}
$$

Bu çalışmada, şehir atmosferinde (Adana-Sarıçam bölgesinde), 7 aylık periyotta gözlemlenen meteorolojik parametrelerdeki değişim ve bunların bronz materyal korozyonu üzerindeki etkileri incelenmiştir. Buna ek olarak, doğrudan açık atmosferde organik ince film ile koruma yönteminin uygulanabilirliği çalışılmıştır. Merkapto-etanol (ME) ve amino-etantiol (AET) organik molekülleri, sahip oldukları $-\mathrm{SH}$ grubu üzerinden bakır metalinin boş $\mathrm{d}$ orbitalleri ile koordinasyona girerek, yüzeyde polimer benzeri çok ince bir film oluşturabilirler. Tarihi bir eser yüzeyinde uygulanacak ince organik filmin mümkün olduğunca homojen olması estetik görünüm açısından tercih edilirken, koruyuculuk açısından da kusurların (çatlaklar, gözenekler vb.) az olması gereklidir. ME, AET ve bu iki bileşiğin karışımı ile hem yüzeyde iyi tutunan hem de moleküller arası etkileşmeler sayesinde kompakt yapıya sahip organik koruyucu film geliştirilmeye çalışılmıştır.

\section{MATERYAL VE METOT}

\subsection{Materyal}

Atmosfere açık ortama bırakılan bronz örnekler, $18 \mathrm{~mm}$ yarıçapa $2 \mathrm{~mm}$ kalınlığa sahip olup bileşimi Çizelge 1'de verilmiştir. Örneklerin yüzeyi önce 1200 gritlik zımpara kâğıdı ile parlatılmıştır. 1:1 etanol/su karışımı ve destile su ile y1kandıktan sonra oda sicaklığında kurutulmuştur. İnhibitörler Sigma Aldrich firmasından temin edilmiştir. İnhibitörlerin yapıları Şekil 1'de gösterilmiştir.<smiles>NCCS</smiles><smiles>OCCS</smiles>

2-amino-etantiol

Şekil 1. Inhibitör moleküllerinin kimyasal yapıları

\subsection{Metot}

Atmosferik korozyon testleri: ASTM G50 standardına göre yuvarlak kesilmiş bronz örnekleri şehir atmosferinde güneye bakan cepheye 45 derece açı ile yerleştirilmiştir. Etanol içerisinde hazırlanan $50 \mathrm{mM}$ derişimdeki inhibitör çözeltileri bronz yüzeylerine $10 \mathrm{~cm}$ uzaklıktan plastik bir sprey şişesi yardımıyla püskürtülerek uygulanmıştır. Her bir püskürtme işleminde, yüzeye uygulanan inhibitör miktarı $2,8 \mathrm{mg} / \mathrm{cm}^{2}$ olacak şekilde ayarlanmıştır.

Yüzey morfolojisi analizleri: Bronz örnekleri, simule asit yağmuru çözeltisinde $(\mathrm{pH}=5)$ ve $50 \mathrm{mM}$ derişime sahip ME, AET ve ME/AET (1:1) karışımı çözeltilerinde bir hafta bekletildikten sonra SEM-EDS cihazı ile görüntülenmiştir. Ayrıca atmosfere birakılan yüzeyler bifokal optik mikroskop (Leica EZ4HD) ve SEM-EDS (A Carl Zeiss Evo 440 SEM) cihazı ile 2 ve 7 aylık süreçlerde incelenmiştir, aynı örneklere ait kesit analizleri ile yüzeydeki değişiklikler aydınlatılmaya çalışılmıştır.

Meteorolojik ve çevresel verilerin eldesi: Meteorolojik ve çevresel irdelemeler için, Meteoroloji Genel Müdürlüğü Adana Sarıçam 
İstasyonu ile Çevre ve Şehircilik Bakanlığı Adana Meteoroloji hava kalitesi izleme istasyonunun düzenli olarak yayınladıkları veriler kullanılmıştır. Ülkemizde ve Avrupa Birliğine üye ülkelerde 2015 yılında uygulanan hava kalitesi sınır değerleri Çizelge 2'de gösterilmiştir [17]. Deneylerin yapıldığı Adana il merkezindeki hava kalitesi değerleri Çizelge 2'de verilen standart değerler ile karşılaştırılarak yorumlanmıştır.

Elektrokimyasal ölçümler ve korozyon hızının belirlenmesi: Potansiyodinamik ölçümler CHI 660B potansiyostat-galvonostat cihazı ile oda sıcaklığında yapılmıştır. Üç elektrot sisteminde çalışma elektrotu bronz, karşı elektrot platin ve referans elektrot $\mathrm{Ag} / \mathrm{AgCl}(\mathrm{KCl})$ kullanılmıştır. $\mathrm{Bu}$ deneylerde test çözeltisi olarak, şehir atmosferinde gerçekleşen asit yağmurlarını simüle eden bileşime $\left(0,2 \mathrm{~g} \mathrm{~L}^{-1} \mathrm{Na}_{2} \mathrm{SO}_{4}+0,2 \mathrm{~g} \mathrm{~L}^{-1} \mathrm{NaHCO}_{3}\right)$ sahip sulu çözelti $(\mathrm{pH}=5)$ kullanılmıştır. Potansiyodinamik ölçümler korozyon potansiyelinden başlamak üzere $1 \mathrm{mV} / \mathrm{s}$ tarama hızında alınmıştır. Elektrokimyasal parametrelerden korozyon akım1, korozyon potansiyeli hesaplanmıştır. Metal, korozyon potansiyeli dolayında dengeye ulaştıktan sonra (1 saat sonra) bu ölçümlere başlanmıştır. Ölçümler, yüzeyine inhibitör çözeltisi püskürtülmüş ve püskürtülmemiş bronz örnekler atmosferik ortamda 2 ay bekletildikten sonra elde edilmiştir.

\section{BULGULAR}

\subsection{Meteorolojik Veriler}

Meteoroloji Genel Müdürlüğü Adana Sarıçam İstasyonu'ndan elde edilen veriler Çizelge 3'te gösterilmiştir. Türkiye'nin güneyinde yer alan Adana 35-38 enlemleri ile 34-46 doğu boylamları arasında konuma sahip 2.300.000 nüfuslu bir şehirdir. Yazları sıcak ve nemli havası ile diğer illerden ayrılmaktadır. Deneyin yapıldığı nokta N37 04'54', ve E35 18 '57', yükseklik 90 m'dir.
Sıcaklık, reaksiyonları ve iyon hareketliliğini artırarak ve yoğunlaşmayı azaltarak iki farklı rol oynar. Genel olarak, sıcaklık değerinde gerçekleşen her $10^{\circ} \mathrm{C}$ 'lik artış bir kimyasal tepkimenin hızını iki katına çıkarmaktadır [18]

Bağıl nemin \%60'dan daha yüksek olduğu durumda atmosfere açık metalik yüzeylerde ince bir film tabakası oluşmaktadır. Yağışın yüksek olduğu aylarda, havada bulunan partiküllerin ve $\mathrm{SO}_{\mathrm{x}}, \mathrm{NO}_{\mathrm{x}}$ gibi gazların da malzeme yüzeyine taşınması artmaktadır. Rüzgâr, aynı zamanda metal yüzeyindeki oluşan nem tabakasının yüzeyde kalma süresi açısından da (1slak-kuru periyotlar) önemlidir. Nem tabakası, içerisinde çözünmüş bileşenlerin varlığında, korozyon hücresinin oluşması için gerekli elektrolit ortamı sağlar. Bu nedenle, yüzeyin 1slak ve kuru periyotlar arasındaki geçiş süresi ve sıklığı korozyon açısından son derece önemlidir. Bu noktada, güneşlenme süresi kadar rüzgârın da etkisi vardır. Meteorolojik verilerde, bağıl nemin en yüksek ve en düşük değerleri verilmekle birlikte, gün içerisinde (gece ve gündüz arasında) sıcaklıklar önemli ölçüde değiştiğinden, atmosferdeki nemin yüzeye etkisi de sürekli değişir. Bu sırada, 1slakkuru periyotlar, kuruma hızı ve kuruma sırasında nem tabakası içinde, iyon vb. derişiminin anlıkta artması söz konusudur. Dolayısıyla, korozyon süreçleri ve hızı da bu olaylardan direkt etkilenir. Görüldüğü üzere, ilgili parametrelerin hiç birisi tek başına, atmosferik korozyonu açıklama veya modelleme için yeterli değildir.

Çizelge 3'te bağıl nemin oldukça yüksek olduğu görülmektedir. Literatürde bağıl nemin yüksekliğinin bakır ve alaşımlarının korozyon hızını artırttığ 1 belirtilmektedir [19]. Bağıl nemin artması bakır(I)oksit $\left(\mathrm{Cu}_{2} \mathrm{O}\right)$ oluşum hızını artırarak, patina oluşumunu sağlamaktadır. $\mathrm{Bu}$ da bronz malzemenin korozyondan korunmasina neden olmaktadir.

Çizelge 1. Bronz elektrotların \% bileşimi

\begin{tabular}{|c|c|c|c|c|c|c|c|c|c|c|}
\hline Bronz & $\mathrm{Cu}$ & $\mathrm{Sn}$ & $\mathrm{Zn}$ & $\mathrm{Fe}$ & $\mathrm{Ni}$ & $\mathrm{Sb}$ & $\mathrm{S}$ & $\mathrm{Al}$ & $\mathrm{Si}$ & $\mathrm{P}$ \\
\hline Bileşim & 86,45 & 6,27 & 5,97 & 0,32 & 0,48 & $<0,002$ & 0,067 & $<0,001$ & $<0,005$ & $<0,005$ \\
\hline
\end{tabular}




\subsection{Hava Kalitesi Verileri}

Adana İli kent merkezi hava kalitesi, sanayi, evsel ısınma, trafik emisyonlarını da içeren birçok kaynak tipinden olumsuz etkilenmektedir. Ayrıca hava akımları dolayısı ile Misır, Tunus, Libya gibi ülkelerden gelen tozlara maruz kalmaktadır. Adana kent merkezinde $\mathrm{PM}_{10}$ değerlerinin yüksekliğinde, iklim ve arazi koşullarının uygunluğundan kaynaklanan yoğun tarım faaliyetleri sonucu oluşan anız yangınlarının katkısı büyüktür. Özellikle Eylül, Ekim, Kasım aylarında yüzbinlerce dekar alanda misir hasatı yapılmasından sonra özellikle şehrin güneyinden ve meteorolojik şartların etkisiyle Mersin ilinin doğusundan anız yangınları sonucu gelen yoğun partikül madde kentte ciddi şekilde hissedilmektedir. Hava kalitesi olçum istasyonlarından alınan altı yıllık veriler değerlendirildiğinde $\mathrm{PM}_{10}$ değerinin her geçen yıl limit değeri aştığı görülmektedir. Deneyin yapıldığı dönem içinde hava kalitesi $\mathrm{PM}_{10}$ değeri $\mathrm{AB}$ ülkelerinin tabi olduğu sınır değerlerinin üstünde kalmaktadır. Sadece ocak ve mart aylarında ülkemizde uygulanan sınır değerin altındadır. Ancak $\mathrm{SO}_{2}$ ve $\mathrm{O}_{3}$ için yıllık ya da yıllık bazda günlük ortalama limit değer aşım sayısı yönünden herhangi bir durum söz konusu görünmemektedir [17]. $\mathrm{NO}_{\mathrm{x}}$ değerleri kasım, aralık, ocak ve şubat aylarında limit değerleri aşarak, korozyonun hızlanmasına neden olacaktır. İl merkezi Akdeniz'e yaklaşık $50 \mathrm{~km}$ uzaklıkta olduğu için tuz rüzgârları ve klorür iyonlarının korozyona etkisi üzerinde durulmamıştır. Adana Sarıçam meteoroloji istasyonu hava kalitesi değerleri Çizelge 4'te gösterilmiştir. Atmosferdeki partikül madde $\left(\mathrm{PM}_{10}\right)$ değeri çap1 10 mikrometre'ye eşit ya da 10 mikrometre'den küçük olan parçacıkların konsantrasyonunu göstermektedir. Dolaysız kaynaktan atmosfere verilebildikleri (birincil) gibi atmosferde de oluşabilmektedirler (ikincil).
Dolaysız kaynaklar; toprak, deniz, volkan tozu ve biyolojik parçalar gibi doğal kaynaklar ve endüstriyel toz ve is gibi insan kökenli kaynaklardır. İkincil kaynaklar; biyolojik ve volkanik gazlardan oluşan sülfatlar, $\mathrm{NO}_{2}$ 'den oluşan nitratlar, uçucu organik bileşiklerden (VOC) oluşan organik maddeler doğal kaynaklardır. Toplam ince partiküllerin \%60'1 insan yapımıdır. Atmosferde kalış süreleri boyutlarına ve hidrofobik/hidrofilik karakterine bağlı olarak birkaç gün ya da birkaç hafta olabilmektedir.

Hava kirleticilerinin birbirleriyle ve bağıl nem ile olan sinerjik etkileşimleri için lineer korelasyon katsayılarının kareleri $\left(\mathrm{R}^{2}\right)$ hesaplanmış ve Çizelge 5'te gösterilmiştir. Benzer kaynaklardan (her türlü yakıt emisyonu) elde edilen $\mathrm{SO}_{2}, \mathrm{NO}_{\mathrm{x}}$ ve $\mathrm{PM}_{10}$ arasında korelasyon saptanmış, ozonun ise diğer kirleticilerle arasında önemli bir korelasyon olmadığı görülmüş, ikincil kirletici olduğu sonucuna varılmıştır. Bağıl nem ile hava kirleticileri arasında ise bir korelasyon saptanmamıştır. Bu durum literatür ile uyumludur.

\subsection{Optik Mikroskop Verileri}

Atmosfere açık ortamda bekleyen bronz ile ME, AET ve AET/ME karışım inhibitör çözeltileri püskürtülen bronz örneklerin yüzeylerinde meydana gelen değişiklikleri gözlemek için optik mikroskop kullanılmıştır. Metallerin yüzeyinden 2 ve 7 ay sonra 264 büyütme ile alınan görüntüler Çizelge 6'da görülmektedir. Herhangi bir işlem uygulanmamış bronz yüzeyindeki patinanın görüntüsü, çeşitli inhibitör çözeltileri püskürtüldükten sonra değişmektedir. $\mathrm{Bu}$ da inhibitörün patina üzerinde, ya da patina ile birlikte yüzeyde koruyucu bir örtü oluşturduğunu göstermektedir.

Çizelge 2. Hava kalitesi sınır değerleri

\begin{tabular}{|l|c|c|c|c|c|}
\hline \multicolumn{1}{|c|}{ Y1llık } & $\begin{array}{c}\mathrm{PM}_{10} \\
\left(\mu \mathrm{g} / \mathrm{m}^{3}\right)\end{array}$ & $\mathrm{SO}_{2}\left(\mu \mathrm{g} / \mathrm{m}^{3}\right)$ & $\mathrm{NO}_{2}\left(\mu \mathrm{g} / \mathrm{m}^{3}\right)$ & $\mathrm{NO}_{\mathrm{x}}\left(\mu \mathrm{g} / \mathrm{m}^{3}\right)$ & $\begin{array}{c}\mathrm{O}_{3}\left(\mu \mathrm{g} / \mathrm{m}^{3}\right) \\
(8 \mathrm{saat})\end{array}$ \\
\hline $\begin{array}{l}\text { Ülkemizde uygulanan } \\
(2015 \text { y1lı })\end{array}$ & 56 & 20 & 56 & 30 & 120 \\
\hline $\begin{array}{l}\text { AB üye ülkelerde } \\
\text { uygulanan }\end{array}$ & 40 & 20 & 40 & 30 & 120 \\
\hline
\end{tabular}


Bronz Yapıtların Atmosferik Korozyonunda Hava Kirleticilerin Etkisi ve İnhibitörle Korunması

Çizelge 3. Adana Sarıçam istasyonu meteorolojik verileri

\begin{tabular}{|c|c|c|c|c|c|c|}
\hline Aylar & $\begin{array}{c}\text { Ortalama } \\
\text { sicaklık }\left({ }^{\circ} \mathrm{C}\right)\end{array}$ & $\begin{array}{l}\text { Maksimum } \\
\text { sicaklık }\left({ }^{\circ} \mathrm{C}\right)\end{array}$ & $\begin{array}{c}\text { Minimum } \\
\text { sicaklık }\left({ }^{\circ} \mathrm{C}\right)\end{array}$ & $\begin{array}{l}\text { Maksimum } \\
\text { bağıl nem }\end{array}$ & $\begin{array}{l}\text { Minimum } \\
\text { bağıl nem }\end{array}$ & $\begin{array}{c}\text { Ortalama } \\
\text { toplam } \\
\text { yağ1ş } \\
\left(\mathrm{kg} / \mathrm{m}^{2}\right)\end{array}$ \\
\hline Ekim'15 & 23,6 & 34 & 15,1 & 97 & 15 & 1,2 \\
\hline Kasım'15 & 17,7 & 27 & 5,1 & 99 & 8 & 0,2 \\
\hline Aralık'15 & 11,9 & 15,7 & 1,3 & 91 & 9 & 0,0 \\
\hline Ocak'16 & 8,6 & 12,8 & 4,7 & 79 & 42 & 2,3 \\
\hline Şubat'16 & 14,0 & 19,7 & 9,0 & 92 & 41 & 1,6 \\
\hline Mart'16 & 15,3 & 21,1 & 9,9 & 89 & 35 & 1,2 \\
\hline Nisan'16 & 19,9 & 31,6 & 9,1 & 89 & 28,6 & 0,2 \\
\hline
\end{tabular}

Çizelge 4. Adana Sarıçam meteoroloji istasyonu hava kalitesi değerleri

\begin{tabular}{|c|c|c|c|c|c|c|}
\hline Aylar & $\begin{array}{c}\mathrm{PM}_{10} \\
\left(\mu \mathrm{g} / \mathrm{m}^{3}\right)\end{array}$ & $\mathrm{SO}_{2}\left(\mu \mathrm{g} / \mathrm{m}^{3}\right)$ & $\mathrm{NO}\left(\mu \mathrm{g} / \mathrm{m}^{3}\right)$ & $\begin{array}{c}\mathrm{NO}_{2} \\
\left(\mu \mathrm{g} / \mathrm{m}^{3}\right)\end{array}$ & $\begin{array}{c}\mathrm{NO}_{\mathrm{x}} \\
\left(\mu \mathrm{g} / \mathrm{m}^{3}\right)\end{array}$ & $\mathrm{O}_{3}\left(\mu \mathrm{g} / \mathrm{m}^{3}\right)$ \\
\hline Ekim'15 & 55 & 4 & 9 & 22 & 30 & 28 \\
\hline Kasım'15 & 66 & 5 & 18 & 30 & 48 & 28 \\
\hline Aralık'15 & 86 & 8 & 24 & 31 & 55 & 27 \\
\hline Ocak'16 & 49 & 6 & 9 & 28 & 37 & 30 \\
\hline Şubat'16 & 60 & 6 & 12 & 21 & 34 & 25 \\
\hline Mart'16 & 44 & 3 & 5 & 25 & 18 & 39 \\
\hline Nisan'16 & 73 & 2 & 4 & 17 & 19 & 37 \\
\hline
\end{tabular}

Çizelge 5. Hava kirleticilerin korelasyon katsayıları kareleri

\begin{tabular}{|c|c|c|c|c|c|}
\hline $\mathbf{R}^{2}$ & Bağıl nem & $\mathrm{PM}_{10}$ & $\mathrm{SO}_{2}$ & $\mathrm{NO}_{\mathrm{x}}$ & $\mathrm{O}_{3}$ \\
\hline Bağ 1 l nem & 1 & 0,01 & 0,21 & 0,41 & 0,46 \\
\hline $\mathrm{PM}_{10}$ & & 1 & $\mathbf{0 , 6 6}$ & $\mathbf{0 , 8 0}$ & 0,28 \\
\hline $\mathrm{SO}_{2}$ & & & 1 & $\mathbf{0 , 6 7}$ & 0,29 \\
\hline $\mathrm{NO}_{\mathrm{x}}$ & & & & 1 & 0,22 \\
\hline $\mathrm{O}_{3}$ & & & & & 1 \\
\hline
\end{tabular}

İnhibitör uygulamaları ile yüzeydeki birikintinin oksit ağırlıklı olmaktan daha çok, organik moleküllerin yüzeyde kimyasal adsorplanması ile oluşan ince bir organik kaplamaya doğru gittiği görülmektedir. Öte yandan, çalışılan atmosfer koşullarında, yüzeyin genellikle homojen bir 
görünüme sahip olduğu ve oyuklanma benzeri hasarların meydana gelmediği de görülmektedir.

\subsection{SEM-EDS Verileri}

Aynı yüzeylerde daha detaylı veri sağlamak için yapılan SEM analiz sonuçları, 7 aylık deney süresi sonunda elde edilen örnekler için Şekil 2'de verilmiştir. Şekil 2a'da atmosfere açık alanda 7 ay bekleyen bronz yüzeyinde oluşan patina filmini morfolojisi görülmektedir.

Şekil 2b'de görüldüğü gibi $50 \mathrm{mM}$ ME çözeltisi püskürtülen bronz yüzeyindeki kaplamanın morfolojisi tamamen farklıdır. İnce de olsa bir patina tabakası oluşması kaçınılmaz olmakla birlikte, organik moleküllerin meydan getirdiği film tabakası açıkça görülmektedir. Organik moleküllerin metal yüzeyinde kimyasal adsorplanması ile oluşabilecek bu film, alttaki metali oksitlenmesini sürdürerek patinanın gelişmesine izin vermemektedir. Söz konusu organik film kararlı ve sürekli olmasına rağmen yer yer çatlakların da bulunduğu görülmektedir. $\mathrm{Bu}$ durum, bu türden organik filmlerin doğası gereğidir, korozyon ancak bu kusurlu bölgeler (defective area) üzerinden sürebilir.
$50 \mathrm{mM}$ AET ile yine püskürtme yöntemi ile yüzeyde oluşturulan koruyucu filmin morfolojisi son derece homojen (uniform) bir kaplamanın varlığına işaret etmektedir. Şekil 2c'de verilen 20.000 büyütmede görülen çatlaklar, örtünün koruyuculuğunun sınırlı olduğunu göstermektedir. Öte yandan, polimer benzeri yüzeyi pürüzsüz bir film tabakasının oluşması organik moleküllerin birbirleri arasında ve yüzeyle etkileşimini çok kuvvetli olduğunu göstermektedir. Makroyap1 tamamen homojen ve kusursuz görünmesine rağmen, 20.000 büyütme ile mikro yapıda kusurların görünmesi, moleküler aras1 etkileşmelerin ve metal yüzeyine tutunmayı sağlayan adhezyon kuvvetlerine bağlı ortaya çıkan olağan bir durumdur. Hem ME hem de AET, sahip oldukları -SH grubu üzerinden metal atomların (özellikle bakır) boş d orbitalleri ile koordinasyona girerek, yüzeyde polimer benzeri çok ince bir film oluşturabilirler [20]. Ancak, AET sahip olduğu amin grubu elde edilen polimerik ince filmlerin morfolojisi üzerinde önemli fark yaratmaktadır. Bu $-\mathrm{NH}_{2}$ grubunun moleküller arası etkileşmeyi güçlendirerek bu olumlu etkiyi yaratmış olduğu anlaşılmaktadır. Tarihi bir eser yüzeyinde uygulanacak ince organik filmin mümkün olduğunca homojen (AET'de olduğu gibi) olması estetik görünüm açısından tercih edilir.

Çizelge 6. İnhibitör çözeltisi püskürtülmemiş bronz ile inhibitör çözeltisi püskürtülmüş bronz örneklerin 2. ve 7. ayda optik mikroskop görüntüleri

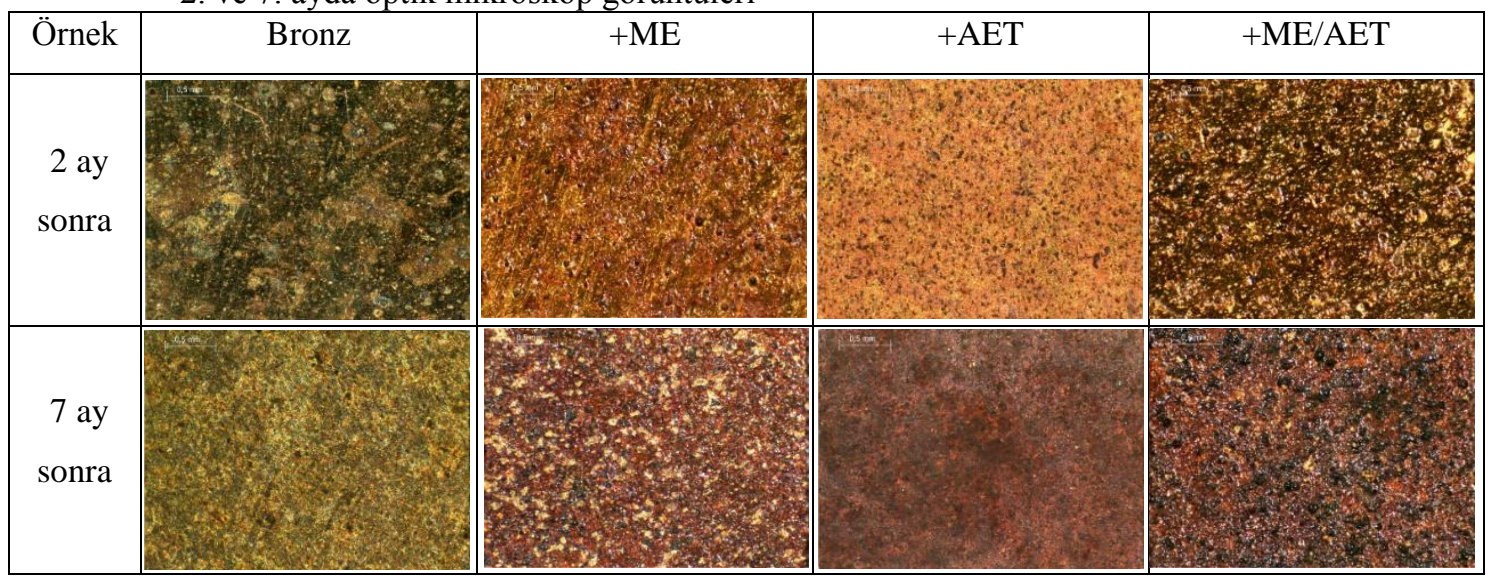

Ayrıca AET/ME karışımı hazırlanmış ve yüzeye uygulanmıştır. Şekil 2d'de görüldüğü gibi $\mathrm{ME}$ püskürtülmüş yüzeye göre daha homojen ve kusurlardan arındırılmış bir organik film elde edilmiştir. Homojen olması, daha önce de vurgulandığı gibi estetik kaybı gerçekleşmeksizin 
koruma sağlanması mümkün görünmektedir. Ancak bu örtü AET püskürtülmüş yüzey kadar homojen ve kompakt değildir.

Şekil 3'te yer verilen kesit SEM mikrograflarından, inhibitör uygulanmış yüzeyde daha ince bir birikinti tabakasının varlığ görülmektedir. Bu durum, yüzeyin inhibitör filmi ile korunduğunu ve korozyona bağlı oksit oluşumunun kismen engellendiğini göstermektedir. Kendi halinde korozyona uğrayan malzemenin yüzeyinde daha yoğun bir oksit tabakası oluşurken, inhibitör filmi uzun süre kararlılığını sürdürerek, az miktarda oksit ile birlikte, yüzeyi korozyona karşı koruyabilmektedir.

Şekil 2'de SEM sonuçlarına yer verilen örneklerin, yüzeyinin tamamını taramak suretiyle elde edilen EDS analiz sonuçları Çizelge 7'de verilmiştir. Bu yöntemle, yüzeyde var olan bileşenlerin (birikinti, organik film, korozyon ürünü vb.) türleri hakkında daha detaylı bilgi elde edilmiștir. Yüzeyine inhibitör filmi uygulaması yapılmamış (şahit) örnek yüzeyinde, zamanla kararlı $\mathrm{Cu}$ (I ve II) oksit bileşiklerinin meydana geldiği oksijen miktarından anlaşılmaktadır. Öte yandan, $\mathrm{Sn}$ ve $\mathrm{Zn}$ miktarlarının, çalışılan bronz numunedeki gerçek yüzdelere kıyasla daha düşük çıkması tamamen yüzeyde biriken $\mathrm{Cu}$ (I, II) oksit filminin varlığıla ilişkilidir.

EDS ölçümü sırasında, gönderilen X-1şını yüzeyden ancak sınırlı bir derinliğe (yaklaşık 1 mikron) kadar ulaşabilir, dolayısıyla alınan sinyaller de ona göre şekillenir. Yüzeydeki örtünün (filmin) kalınlığı, homojenliği ve kompakt olup olmamasına bağlı olarak, alttaki baz metalden alınacak sinyaller zayıflayabilir, hatta gözlenemeyebilir. $\mathrm{Bu}$ çerçevede, elde edilen sonuçlar genel olarak yüzeydeki örtünün (birikinti, film vb.) karşılaştırmalı değerlendirilmesinde kullanılmıştır.
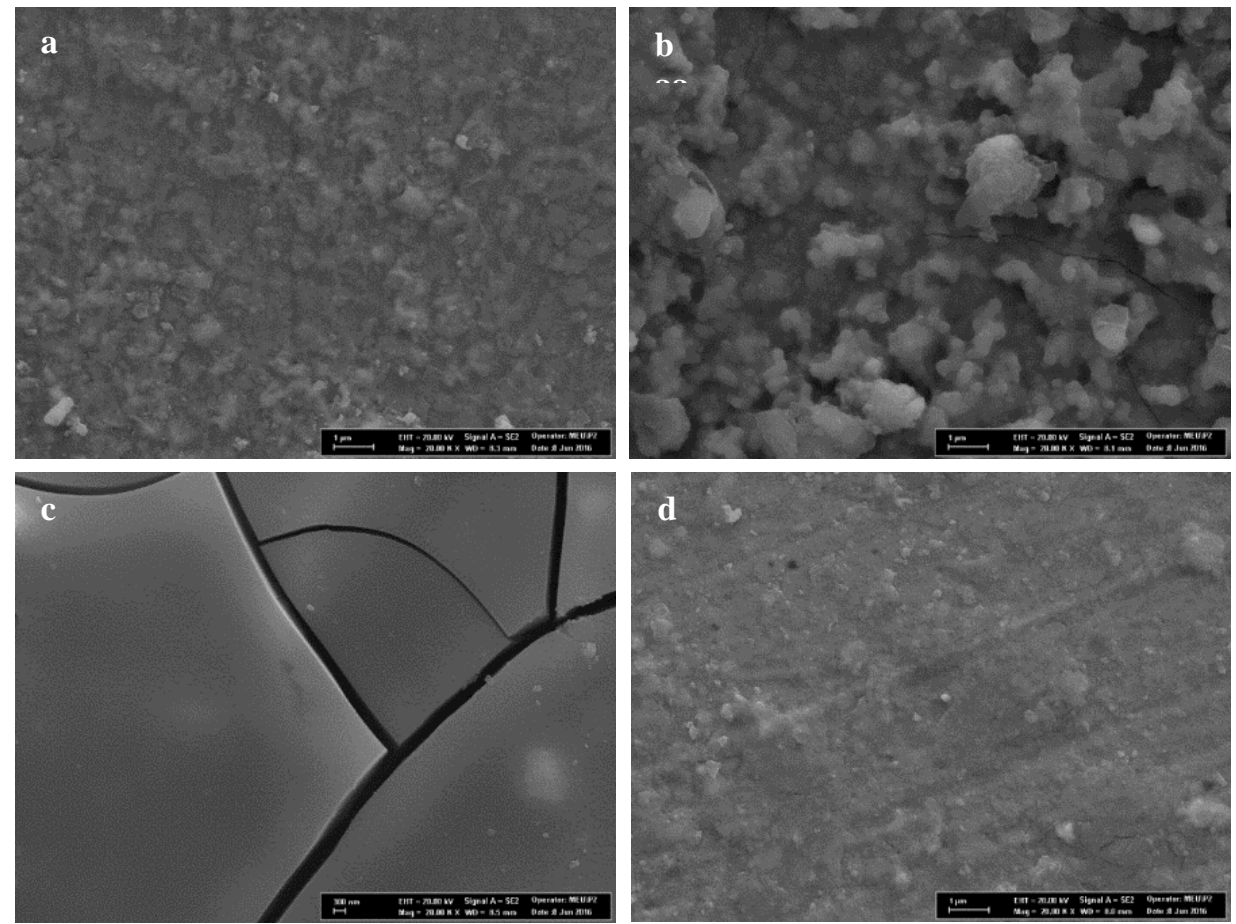

Şekil 2. Bronz örnekler için 7 ay atmosferik şartlarda beklemiş yüzeye ait SEM görüntüleri; a: şahit yüzey, b: $50 \mathrm{mM}$ ME püskürtülen yüzey, c: $50 \mathrm{mM}$ AET püskürtülen yüzey, d: $50 \mathrm{mM}$ AET/ME karışımı püskürtülen yüzey. 

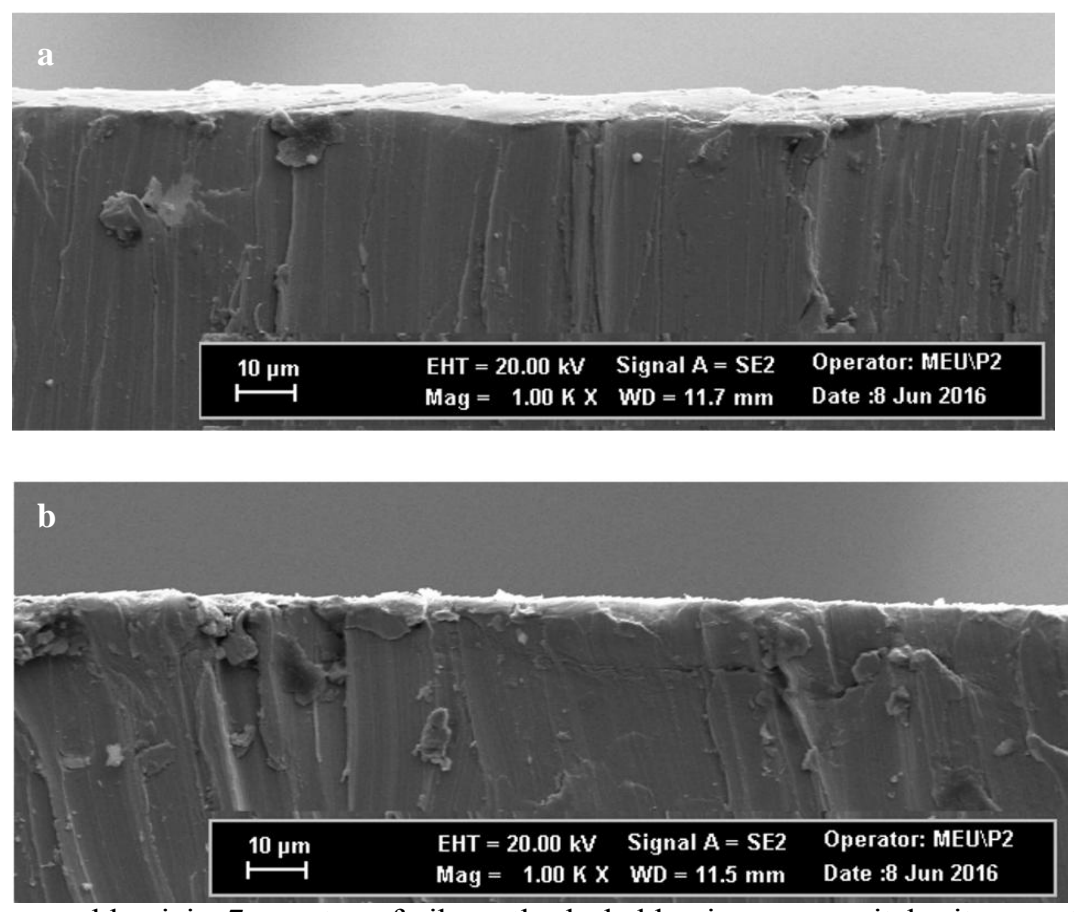

Şekil 3. Bronz örnekler için 7 ay atmosferik şartlarda beklemiş yüzeye ait kesit görüntüleri; a: Şahit yüzey, b: $50 \mathrm{mM}$ AET püskürtülen yüzey

Çizelge 7. Bronz örnekler için 7 ay atmosferik şartlarda beklemiş yüzeyin EDS sonuçları

\begin{tabular}{|c|c|c|c|c|}
\hline Örnek & Şahit $(\%$ wt $)$ & + ME $(\%$ wt $)$ & + AET $(\%$ wt $)$ & +AET/ME $(\%$ wt $)$ \\
\hline $\mathrm{Cu}$ & 78,41 & 77,11 & 31,16 & 67,85 \\
\hline $\mathrm{Sn}$ & 5,68 & 1,27 & 1,42 & 3,35 \\
\hline $\mathrm{Zn}$ & 5,42 & 1,16 & 2,07 & 2,50 \\
\hline $\mathrm{S}$ & 1,82 & 5,49 & 36,79 & 13,34 \\
\hline $\mathrm{N}$ & 1,26 & 0 & 4,67 & 2,63 \\
\hline $\mathrm{O}$ & 7,41 & 13,46 & 14,15 & 7,77 \\
\hline $\mathrm{C}$ & 0 & 1,51 & 9,74 & 2,56 \\
\hline
\end{tabular}

Şahit numunede, karşılaşılan kükürt ve azota ait sinyaller, atmosferde yer alan kirleticilerin zaman içerisinde, yüzeyle etkileşmelerinin sonucudur. $\mathrm{Bu}$ süreçlerin neticesinde, yüzeyde oluşan bakır (I, II) oksit birikintisinin azot ve kükürt içeren anyonları da içere daha kompleks yapıdaki patina türleri $\left(\mathrm{Cu}_{4} \mathrm{SO}_{4}(\mathrm{OH})_{6}, \mathrm{Cu}_{4} \mathrm{SO}_{4}(\mathrm{OH})_{6} \cdot \mathrm{H}_{2} \mathrm{O}, \mathrm{Cu}_{2}(\mathrm{OH})_{3} \mathrm{NO}_{3}\right.$, Yüzey organik film ile korunduğundan, patina gelişimi yavaşlamış ve sonuç olarak bakır miktarı
$\left.\mathrm{Cu}_{4} \mathrm{SO}_{4}(\mathrm{OH})_{6} \cdot 2 \mathrm{H}_{2} \mathrm{O}, \quad \mathrm{Cu}_{2} \mathrm{SO}_{4}(\mathrm{OH})_{4}\right) \quad$ olduğunu düşündürmektedir [21-23]. Yüzeye ME filmi uygulanan bronz örnek yüzeyindeki örtü/tabaka içinde bakır miktarının azalmış olması ve aynı zamanda kükürt miktarının arttığı görülmektedir. Bunlara ek olarak gözlenen karbon miktarı da, yüzeyde organik filmin varlığına işaret etmektedir. düşük çıkmıştır. AET filmin uygulandığı örnekte ise, bakır miktarının çok daha düşük çıkması, daha 
önceki kısımda SEM görüntülerinin sağladığı ipuçları ile son derece uyumludur. Yine beklendiği gibi organik bileşiğin yapısında bulunan azotun da yapıya girmesi ile azot miktarı yüksek gözlenmiştir. AET/ME karışımı yüzeye uygulandığında, patina gelişiminin önemli oranda yavaşladığ 1 ve yüzeyin organik film tarafından korunduğu görülmektedir. Oksijen miktarının, tüm inhibitör uygulanmış örneklerde yüksek çıkması organik molekülde (ME) bulunan oksijen varlığıyla ilgilidir. Doğal olarak, az miktarda olsa bakır oksitler de bulunacağından, oksijen miktarı hep yüksek gözlenmiştir.

\subsection{Elektrokimyasal Testler}

Korozyon hızı hakkında sayısal veri elde edebilmek amaciyla, örnekler üzerinde elektrokimyasal testler de yapılmıştır. $\mathrm{Bu}$ doğrultuda aşağıda şematik olarak verildiği gibi bir hücre tasarlanmış ve ölçümler, alttaki bronz örnek çalışma elektrotu olacak şekilde bu hücrede geçekleştirilmiştir (Şekil 4). Hücreye doldurulan korozif test çözeltisi; $0.2 \mathrm{~g} \mathrm{~L}^{-1} \mathrm{Na}_{2} \mathrm{SO}_{4}+0.2 \mathrm{~g} \mathrm{~L}^{-1}$ $\mathrm{NaHCO}_{3} \quad\left(\mathrm{H}_{2} \mathrm{SO}_{4}\right.$ ile $\mathrm{pH} \quad 5$ olacak şekilde ayarlanmıştır) olarak tercih edilmiştir. Şehir atmosferinde gerçekleşen yağmur suyunu temsil etmektedir. $\mathrm{Bu}$ çözelti, metalik malzeme yüzeyinde atmosferik korozyonun geçekleşmesine yol açan, nem tabakası ile aynı işlevi görmektedir.

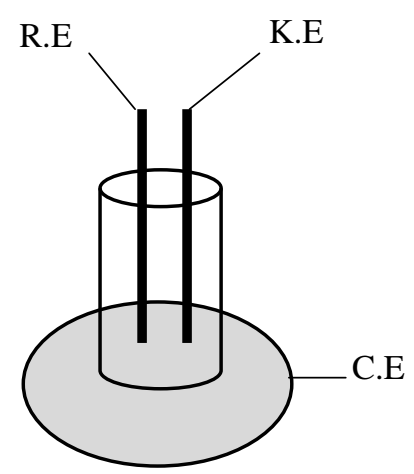

Şekil 4. Elektrokimyasal hücrenin şematik gösterimi (K.E: karşı elektrot, R.E: referans elektrot, C.E: çalışma elektrotu)

Bu çözeltide, hiçbir ön işlem yapılmamış bronz örnek (şahit) 1 saat bekletildikten sonra alınan anodik polarizasyon eğrisinden açıkça görüldüğü gibi, elektrot yüzeyi oldukça kararlı bir oksit filmi ile hızla kaplanmaktadır (Şekil 5a). Bu örtü, daha önce SEM-EDS analizlerinden açıç̧a görüldüğü üzere $\mathrm{Cu}$ (I, II) oksit bileşiklerinden oluşmaktadır. Ancak bu film gözenekli yapıda olduğu ve yer yer kusurlar barındırdığından (tamamen homojen ve kompakt olmadığından) yüzeyin açık kalan yerlerinde anodik çözünme (diğer deyişle korozyon) gerçekleşebilmektedir. Öte yandan, ortam pH'sı ve içerdiği iyonların da etkisi ile oksit film yer yer deforme olabilmektedir. Bunların sonucunda, anodik yönde (korozyon potansiyelinden daha pozitif) yapilan potansiyel taraması sırasında, geniş bir potansiyel aralığında neredeyse sabit akım gözlenmektedir. Metal yüzeyinin korunaklı olmaması halinde, bu tarama sırasında potansiyele bağlı olarak akım değerinin sürekli artması gözlenirdi [24]. Diğer deyişle, anodik potansiyel altında çözünmenin çok daha hızlı olması gerekirken, uygulanan potansiyele rağmen çözünme hızlandırılamamaktadır. Korozyon potansiyeli $\left(\mathrm{E}_{\mathrm{korr}}\right)$ değerinden 200-250 mV daha pozitif değerlere ulaşıldığında ancak yüzeydeki oksit tabakası zarar görmekte ve açılan yüzeyde çözünme hızlanmaktadır. Geniş bir aralıkta yüzeyi oksit filmi ile pasifleşmiş bir malzemenin tipik davranışı gözlenmektedir. $\mathrm{Bu}$ çerçevede, yüzeyden geçen akımın pasiflik akımı $\left(i_{p}\right)$ büyüklüğünde bir anodik çözünme (diğer deyişle korozyon) gerçekleşebileceğinden, bu $\mathrm{i}_{\mathrm{p}}$ değeri korozyon hızı olarak değerlendirilebilir. Dikkat edilirse, yüzeyin pasif durumda olması korozyonun hiç olmayacağı anlamına gelmemektedir, yavaş da olsa korozyon devam etmektedir. Korozyon ürünlerinin sürekli oluşması yüzeyde giderek estetik kaybına ve uzun periyotlarda kalıcı deformasyonlara yol açacaktır.

Katodik polarizasyon eğrileri incelendiğinde, akım değerlerinin her bir örnek için farklı seviyelerde sabit kalma eğiliminde olduğu görülmektedir (Şekil 5b). Potansiyel negatif (katodik) yönde değiştirilirken, akım değerinin sabit kalması "sınır akımı" olarak değerlendirilir ve yüzeyde gerçekleşen katodik indirgenme tepkimesinin (oksijen indirgenmesi) difüzyon hızı ile sınırlı 
olduğunu gösterir. Bu durumda, yüzeydeki birikinti (oksit veya organik film) oksijenin alttaki malzeme yüzeyine ulaşmasını engelleyici bariyer gibi davranmaktadır. En düşük akım AET filmi varlığında ölçüldüğünden, bu filmin katodik olayı da yavaşlattığını göstermektedir. Doğal şartlarda korozyona uğrayan malzemede katodik olay (oksijen indirgenmesi) ile anodik olay (metalin çözünmesi) birbiriyle eşlenik ve aynı hızda gerçekleşmek zorunda olduğundan, AET filmi katodik olayı yavaşlatarak da korozyon hızını düşürmektedir.
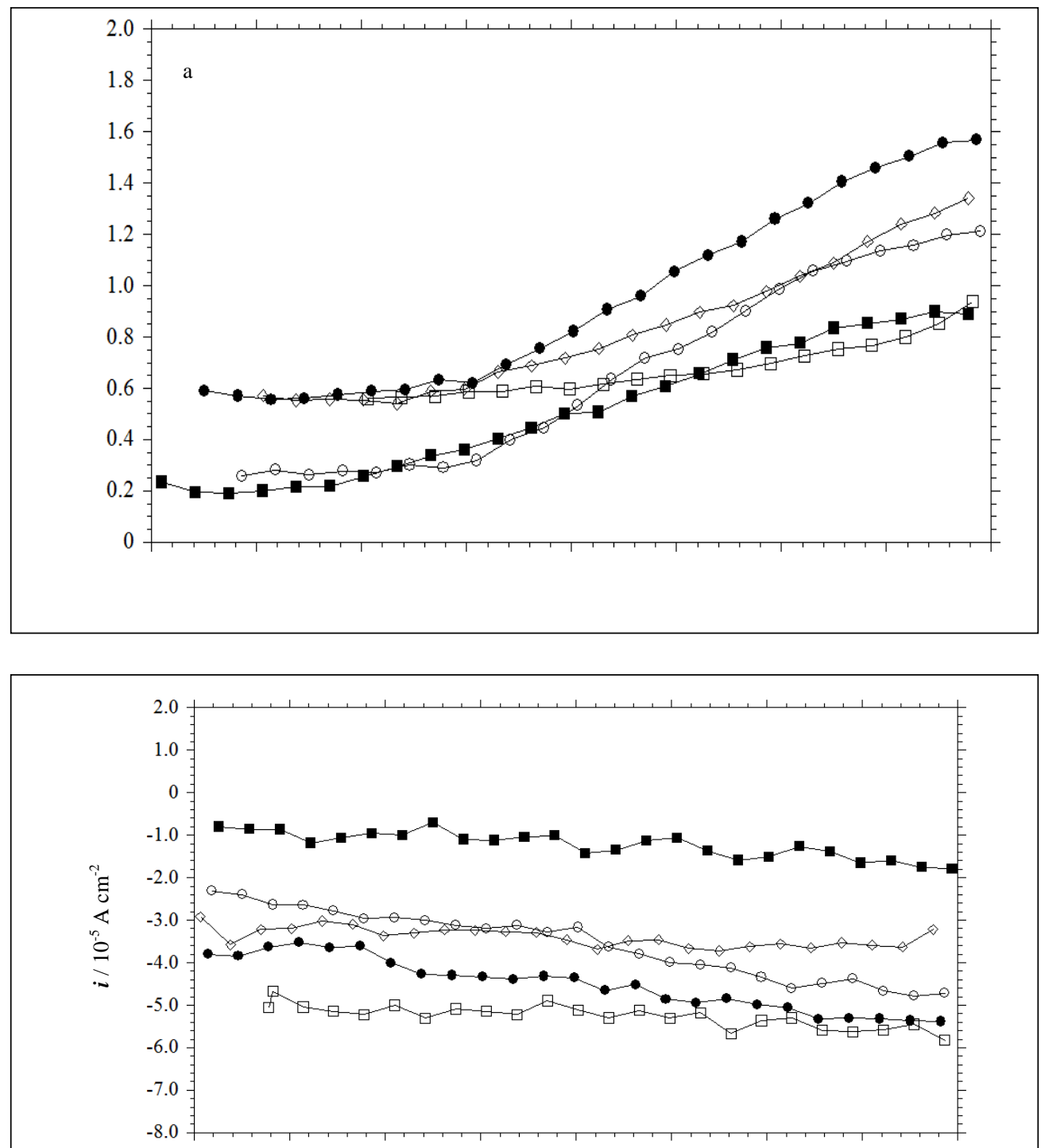

Şekil 5. Bronz için potansiyodinamik a) anodik b) katodik polarizasyon eğrileri ; ०: 1 saat şahit, •: 2 ay şahit, $\square: 2$ ay asit yağmuru çözeltisinde ME püskürtülmüş, $\mathbf{~ : ~} 2$ ay asit yağmuru çözeltisinde AET püskürtülmüş, $\diamond: 2$ ay asit yağmuru çözeltisinde $\mathrm{AET} / \mathrm{ME}$ püskürtülmüş 


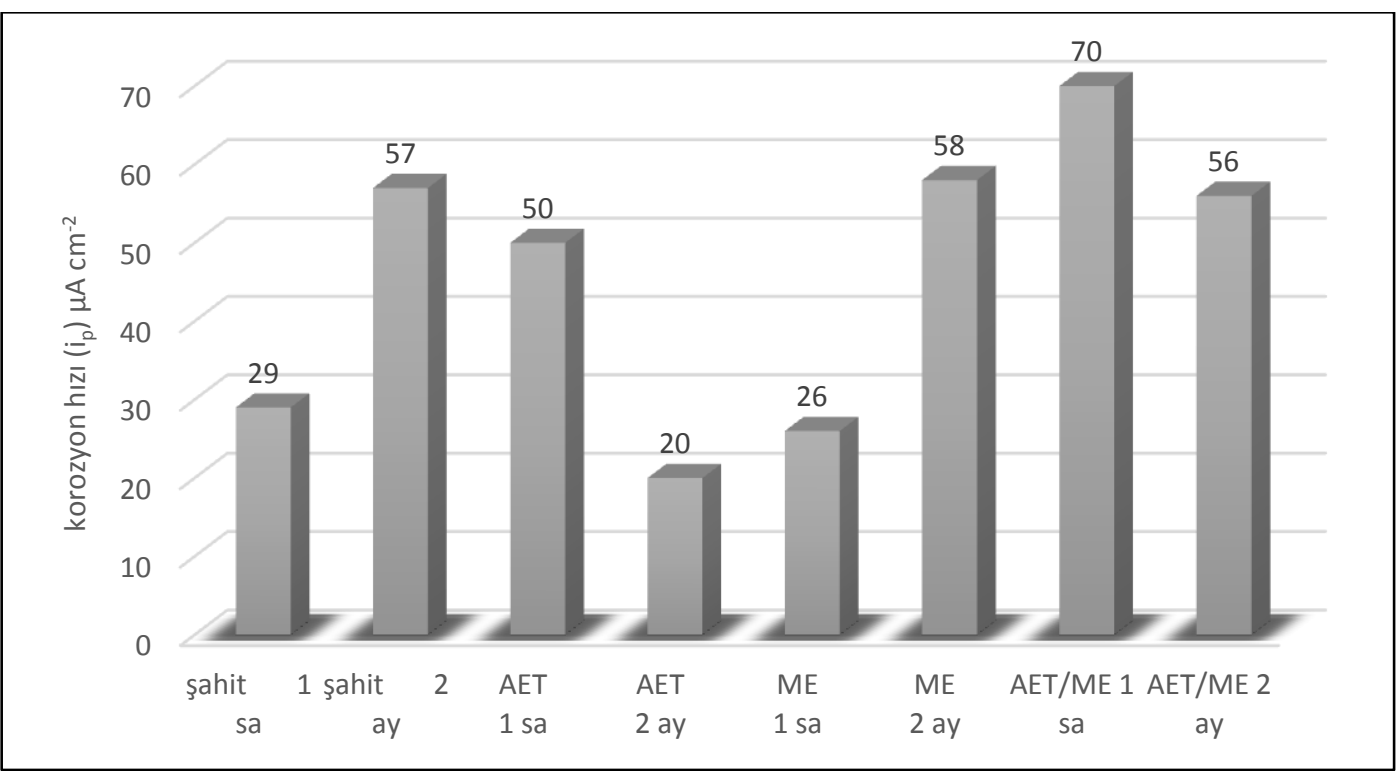

Şekil 6. İnhibitör uygulanmış ve uygulanmamış bronz örneklerin korozyon hızlarının zamanla değişimi

Yüzeyde inhibitör uygulaması yapılmamış bronz örneklerde korozyon hızının zaman içerisinde dikkate değer bir değişim sergilemediği de net olarak görülmektedir (Şekil 6). Organik film uygulandığ1 durumda, korozyon hızlarının biraz daha düşük gerçekleştiği, bu elektrokimyasal test sonuçlarından görülmektedir. Önceki kısımda yer verilen SEM-EDS sonuçları da göz önünde bulundurulduğunda, yüzeyde ince bir organik koruyucu film oluşturularak, yüzeyde korozyona bağlı patina oluşumu önlenebilmektedir. $\mathrm{Bu}$ sonuçlara göre, bronz yüzeyi doğal oksit tabakası yerine, kolayca uygulanabilen ve istenilen siklıkta yenilenmesi mümkün olan organik film ile korunması mümkündür. Doğal bakır oksit ile karşılaştırıldığında, organik filmin daha hidrofobik yapıda olması da korozif bileşenlerin, su ile birlikte yüzeye taşınmasını zorlaştırması beklenmelidir [25,26]. AET/ME karışımı uygulandığında korozyon hızı, şahit numuneye kıyasla biraz daha yüksek ölçülmüştür. Bu durumun, bronz yüzeyinde doğal olarak meydana gelen koruyucu özellikte oksit benzeri korozyon ürünleri ile ilgili olduğu düşünülmektedir. Şahit numune yüzeyinde oluşan bu tabaka malzemeye belirli bir koruma zaten sağlamaktadır. Başlangıçta hızla oluşan bu oksit tabakası, uzun vadede güvenilir olmadığı için oksit fazı ile uyumlu çalışacak ve kolayca uygulanabilen organik bir inhibitör ile koruyuculuğun arttırılmas1 planlanmıştır. AET/ME karışımı uygulandığında, olumlu bir etki gözlenmediği gibi, bu karışımın yüzeyle etkileşimi sonucu, oksit filminin koruyuculuğuna da olumsuz etki yapabildiği anlaşılmaktadır. Öte yandan, uzun süreli performanslar dikkate alındığında AET inhibitörü kullanılması durumunda, en düşük korozyon hızı ölçülmüştür. Korozyon hızlarındaki değişimden görüldüğü gibi AET uygulaması ile en düşük korozyon hızı gerçekleşmektedir. ME ile AET inhibitörlerin molekül yapıları karşılaştırıldığında her ikisinde -SH grubu ortak iken, ME molekülünde $-\mathrm{OH}$, AET molekülünde $-\mathrm{NH}_{2}$ grubu yer almaktadır. AET molekülünde bulunan amin grubu, yüzeyde film oluşturabilmekte ve metal/metal iyonu ile daha kuvvetli etkileşim sağlamaktadır. $\mathrm{Bu}$ etki deneysel sonuçlardan açıkça görülmektedir.

\section{SONUÇLAR}

Açık havada tutulan bronz yapıtların, atmosferde bulunan kirleticilerin türüne ve miktarına bağlı olarak, yüzeyde farklı tip patinalar oluşmaktadır. $\mathrm{Bu}$ patina tabakası sınırlı bir koruma 
sağlayabildiğinden, zaman içerisinde yüzeyde hem estetik kaybı hem de kalıcı tahribat meydana gelebilmektedir. Kendi doğal korozyon ürünleri yerine, yüzeye basit bir püskürtme işlemi ile uygulanabilen organik inhibitörlerin oluşturduğu polimerik film ile daha etkin bir koruma sağlanabilmektedir. Bronz yüzeyinde kimyasal olarak adsorplanan bu moleküllerin oluşturduğu organik film, kendiliğinden oluşan az miktardaki oksit ile birlikte nem filmi oluşumunu sinırlanmakta ve havadaki kirleticilerin etkisini de azaltmaktadır. Numunelerin yerleştirildiği Sarıçam bölgesi için meteorolojiden sağlanan ayrıntılı bilgiler yardımıyla, atmosferik korozyon yedi ay süre ile incelenmiştir. 2-merkapto-etanol (ME), 2-amino-etanetiol (AET) bileşikleri ve AET/ME $(1: 1)$ karışımının inhibitör etkinlikleri karşılaştırmalı olarak değerlendirilmiş ve 2-amino-etanetiol'un (AET) en etkin korumayı sağladığı sonucuna ulaşılmıştır. SEM sonuçlarından görüldüğü üzere, karışım ile elde edilen organik filmin homojen ve s1k1 olması yanında organik moleküllerin yapısı itibariyle yüzeyde sağlanan hidrofob etki önemlidir. Atmosferik korozyonun gerçekleşmesi için havadaki su buharının malzeme yüzeyinde yoğuşması gerekmektedir ve nem filmi oluşması sınırlandığı ölçüde korozyon da yavaşlamaktadır.

\section{TEŞEKKÜR}

Yazar çalışmaya sağladığı destekten dolayı ÇÜBAP (Çukurova Üniversitesi Rektörlüğü Bilimsel Araştırma Projeleri Koordinasyon Birimi, FBA-2015-4034)'a teşekkür eder.

\section{KAYNAKLAR}

1. Tidblad, J., Kucera, V., Mikhailov, A.A. 1998. UN/ECE International Co-operative Programme on Effects on Materials, Including Historic and Cultural Monuments, Swedish Corrosion Institue, Sweden.

2. Mendoza, A.R., Corvo, F., 2000. Outdoor and Indoor Atmospheric Corrosion of Non-ferrous Metals. Corrosion Science 42: 1123-1147.
3. Arroyave, C., Morcillo, M., 1995. The Effect of Nitrogen Oxides in Atmospheric Corrosion of Metals. Corrosion Science 37: 293-305.

4. Fabjan, E. S., Kosec, T., Kuhar, V., Legat, A., 2011. Corrosion Stability of Different Bronzes in Simulated Urban Rain, Materials and Technology 45: 585-591.

5. Syed, S., 2006. Atmospheric corrosion of Materials, Emirates Journal for Engineering Research 11: 1-24.

6. Watt, J., Tidblad, J., Kucera, V., Hamilton, R., 2009. The Effects of Air Pollution on Cultural Heritage, Springer, New York, USA.

7. Yatkın, S., Bayram, A., 2007. İzmir Havasında Partikül Madde Kirliliği: Ölçüm ve Değerlendirme, DEÜ Mühendislik Fakültesi Fen ve Mühendislik Dergisi 9: 15-27.

8. Fenger, J., Hertel, O., Palmgren, F., 1998. Urban Air Pollution-European Aspects, Springer Science+Business Media Dordrecht, Denmark.

9. Liao, X., Cao, F., Chen, A., Liu, W., Zhang, J., Cao, C., 2012. In Situ Investigation of Atmospheric Corrosion Behavior of Bronze under Thin Electrolyte Layers Using Electrochemical Technique, Transaction Nonferrous Metals Society of China 22: 12391249.

10. Mendoza, A.R., Corvo, F., 1999. Outdoor and Indoor Atmospheric Corrosion of Carbon Steel. Corrosion Science 41: 75-86.

11. Gerengi, H., Bereket, G., Kurtay, M., 2016. A Morphological and Electrochemical Comparison of the Corrosion Process of Aluminum Alloys under Simulated Acid Rain Conditions, Journal of the Taiwan Institute of Chemical Engineers, 58: 509-516.

12. Feliu, S., Mariaca, L., Simancas, J., Gonzales, J. A., Morcillo, M., 2003. Effect of $\mathrm{NO}_{2}$ and/or $\mathrm{SO}_{2}$ Atmospheric Contaminants and Relative Humidity on Copper Corrosion, Revista Metal Madrid 39: 279-288.

13. Wadsak, M., Aastrup, T., Odnevall Wallinder, I., Leygraf, C., Schreiner, M., 2002. Multianalytical in Situ Investigation of the Initial Atmospheric Corrosion of Bronze, Corrosion Science 44: 791-802.

14. Nord, A.G., Tronner, K., Boyce, J., 2001. Atmospheric Bronze and Copper Corrosion as 
an Environmental Indicator, Water, Air, and Soil Pollution 127: 193-204.

15. Hettiarachchi, S., 1991. The Effects of Ozone on Corrosion of Steel and Copper in Cooling Water Systems, Corrosion'91, Paper 206 (edited by NACE International) Houston, TX.

16. Brown, B.E., Duquette Rensselaer, D.J., 1993. The Effects of Dissolved Ozone on the Corrosion Behavior of 304 Stainless Steel, Monel 400 and Naval Brass in Artificial Sea Water, Polytechnic Institute Materials Engineering Department Final Report to the Office of Naval Research, Troy, New York.

17. Yüksek, A., Can, J., Dinçer, K. V., Oğuzhan, S., Sabah, I., 2013. Çevre ve Şehircilik Bakanlığ1 ve Adana Büyükşehir Belediyesi, Hava Kalitesi Değerlendirme Raporu, Adana.

18. Portella, M.O.G., Portella, K.F., Pereira, P.A.M., Inone, P.C., Brambilla, K.J.C., Cabussu, M.S., Cerqueira, D.P., Salles, R.N., 2012. Atmospheric Corrosion Rates of Copper, Galvanized Steel, Carbon Steel and Aluminum in the Metropolitan Region of Salvador, BA, Northeast Brazil, Procedia Engineering 42: 171-185.

19. Liu, B., Wang, D.W., Guo, H., Ling, Z.H., Cheung, K., 2015. Metallic Corrosion in the Polluted Urban Atmosphere of Hong Kong, Environmental Monitoring and Assessment, 187:4112-4122.

20.Zerjav G., Lanzutti A., Andreatta F., Fedrizzi L., Milosev I., 2016. Characterization of SelfAssembled Layers Made with Stearic Acid, Benzotriazole, or 2-Mercaptobenzimidazole on Surface of Copper for Corrosion Protection in Simulated Urban Air. Materials and Corrosion, in Press.

21. FitzGerald K.P., Nairn J., Skennerton G., Atrens, A., 2006. Atmospheric Corrosion of Copper and the Colour, Structure and Composition of Natural Patinas on Copper. Corrosion Science 48: 2480-2509.

22. He, L., Liang, J., Jiang, B., 2011. Corrosion Behavior and Morphological Features of Archeological Bronze Coins from Ancient China, Microchemical Journal, 99: 203-212.

23. Robiola, L., Blengino, J.M., Fiaud, C., 1998. Morphology and Mechanisms of Formation of
Natural Patinas on Archeological Cu-Sn Alloys, Corrosion Science 40: 2083-2111.

24. Chiavari, C., Bernardi, E., Balbo, A., Monticelli, C., Raffo, S., Bignozzi, M.C., Martini, C., 2015. Atmospheric Corrosion of Fire-Gilded Bronze: Corrosion and Corrosion Protection During Accelerated Ageing Tests. Corrosion Science, 100: 435-447.

25. Kosec, T., Legat, A., Milosev, I., 2010. The Comparison of Organic Layers on Bronze and Copper. Progress in Organic Coatings 69: 199-206.

26.Zerjav, G., Milosev, I., 2015. Protection of Copper Against Corrosion in Simulated Urban Rain by the Combined Action of Benzotriazole, 2-Mercaptobenzimidazole and Stearic Acid, Corrosion Science 98: 180-191. 